\title{
Propagation of the Madden-Julian
}

Oscillation through the Maritime Continent and scale interaction with the diurnal cycle of precipitation

Article

Published Version

Peatman, S. C., Matthews, A. J. and Stevens, D. P. (2014) Propagation of the Madden-Julian Oscillation through the Maritime Continent and scale interaction with the diurnal cycle of precipitation. Quarterly Journal of the Royal Meteorological Society, 140 (680). pp. 814-825. ISSN 0035-9009 doi: https://doi.org/10.1002/qj.2161 Available at https://centaur.reading.ac.uk/37112/

It is advisable to refer to the publisher's version if you intend to cite from the work. See Guidance on citing.

To link to this article DOI: http://dx.doi.org/10.1002/qj.2161

Publisher: Wiley

All outputs in CentAUR are protected by Intellectual Property Rights law, including copyright law. Copyright and IPR is retained by the creators or other copyright holders. Terms and conditions for use of this material are defined in the End User Agreement. 


\section{www.reading.ac.uk/centaur}

\section{CentAUR}

Central Archive at the University of Reading

Reading's research outputs online 


\title{
RMetS
}

\section{Propagation of the Madden-Julian Oscillation through the Maritime Continent and scale interaction with the diurnal cycle of precipitation}

\author{
Simon C. Peatman, ${ }^{\mathrm{a}}{ }^{\star}$ Adrian J. Matthews ${ }^{\mathrm{a}, \mathrm{b}}$ and David P. Stevens ${ }^{\mathrm{a}}$ \\ ${ }^{a}$ School of Mathematics, University of East Anglia, Norwich, UK \\ ${ }^{\mathrm{b}}$ School of Environmental Sciences, University of East Anglia, Norwich, UK \\ ${ }^{\star}$ Correspondence to: S. C. Peatman, School of Mathematics, University of East Anglia, Norwich NR4 7TJ, UK. \\ E-mail: s.peatman@uea.ac.uk
}

The convectively active part of the Madden-Julian Oscillation (MJO) propagates eastward through the warm pool, from the Indian Ocean through the Maritime Continent (the Indonesian archipelago) to the western Pacific. The Maritime Continent's complex topography means the exact nature of the MJO propagation through this region is unclear. Model simulations of the MJO are often poor over the region, leading to local errors in latent heat release and global errors in medium-range weather prediction and climate simulation.

Using 14 northern winters of TRMM satellite data it is shown that, where the mean diurnal cycle of precipitation is strong, $80 \%$ of the $\mathrm{MJO}$ precipitation signal in the Maritime Continent is accounted for by changes in the amplitude of the diurnal cycle. Additionally, the relationship between outgoing long-wave radiation (OLR) and precipitation is weakened here, such that OLR is no longer a reliable proxy for precipitation. The canonical view of the $\mathrm{MJO}$ as the smooth eastward propagation of a large-scale precipitation envelope also breaks down over the islands of the Maritime Continent. Instead, a vanguard of precipitation (anomalies of $2.5 \mathrm{~mm} \mathrm{day}^{-1}$ over $10^{6} \mathrm{~km}^{2}$ ) jumps ahead of the main body by approximately 6 days or $2000 \mathrm{~km}$. Hence, there can be enhanced precipitation over Sumatra, Borneo or New Guinea when the large-scale MJO envelope over the surrounding ocean is one of suppressed precipitation.

This behaviour can be accommodated into existing MJO theories. Frictional and topographic moisture convergence and relatively clear skies ahead of the main convective envelope combine with the low thermal inertia of the islands, to allow a rapid response in the diurnal cycle which rectifies onto the lower-frequency MJO. Hence, accurate representations of the diurnal cycle and its scale interaction appear to be necessary for models to simulate the MJO successfully.

Key Words: $\quad$ equatorial waves; Matsuno-Gill model; MJO propagation mechanism; TRMM

Received 30 August 2012; Revised 21 January 2013; Accepted 10 March 2013; Published online in Wiley Online Library 2 May 2013

Citation: Peatman SC, Matthews AJ, Stevens DP. 2014. Propagation of the Madden-Julian Oscillation through the Maritime Continent and scale interaction with the diurnal cycle of precipitation. Q. J. R. Meteorol. Soc. 140: 814-825. DOI:10.1002/qj.2161 


\section{Introduction}

The Maritime Continent (Figure 1) is a region of many islands and shallow oceans, located within the tropical warm pool, and is home to over 350 million people. The importance of the Maritime Continent to the global climate was identified by Ramage (1968). Due to the high sea surface temperature in the region, there is heavy precipitation there, accompanied by significant latent heat release. It is this release of energy which makes the Maritime Continent one of the main drivers of the global atmospheric circulation; hence, it is often known as an atmospheric 'boiler box' (e.g. Simpson et al., 1993; Neale and Slingo, 2003).

The relatively coarse resolution used by general circulation models (GCMs) means that the land where the precipitation is focused is poorly resolved. GCMs are also unable to resolve convective weather systems, so convection must be parametrized. However, experiments with GCMs by Yang and Slingo (2001) found significant errors in the parameterized precipitation over the Maritime Continent, and the resulting systematic dry bias is responsible for errors which propagate globally in models (Neale and Slingo, 2003). Therefore, there is a need to improve the understanding and simulation of organized Maritime Continent convection.

Daytime insolation over the Maritime Continent establishes a temperature contrast between land and sea, since the land has a lower heat capacity. As a result, convective precipitation is concentrated mainly over the land due to convergence of sea breezes and ascent of moist air over the islands (Qian, 2008). The crucial role played by insolation means that the precipitation over both the land and the sea exhibits a strong diurnal cycle (e.g. Gray and Jacobson, 1977; Yang and Slingo, 2001; Nesbitt and Zipser, 2003). The land experiences little or no precipitation in the morning before heavy convection forms in the afternoon and evening, moving inwards from the coast (e.g. Borneo) or forming on the flanks of mountains (e.g. Sumatra, New Guinea; Figure 2). Overnight, land-based precipitation decays or may propagate offshore (e.g. southwest coast of Sumatra, northwest coast of Borneo, north coast of New Guinea). The oceanic diurnal cycle, which has a much weaker amplitude than that over land, peaks during the morning before decaying throughout the afternoon and evening.

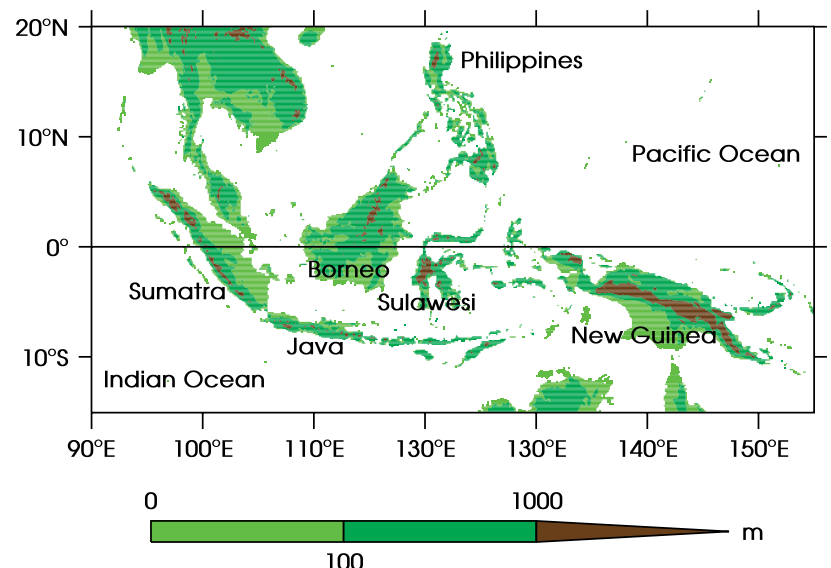

Figure 1. GLOBE topography $(\mathrm{m})$ of the Maritime Continent, regridded to $0.11^{\circ}$ resolution, with oceans and major islands and island groups labelled. This figure is available in colour online at wileyonlinelibrary.com/journal/qj
On intraseasonal time-scales, the chief source of variability in the Tropics is the Madden-Julian Oscillation (MJO) (Madden and Julian, 1971, 1972, 1994; Zhang, 2005). A convectively active envelope propagates slowly $\left(\sim 5 \mathrm{~m} \mathrm{~s}^{-1}\right)$ eastwards, generally starting in the Indian Ocean, followed by a convectively suppressed region behind it. However, the skill of GCMs at forecasting the evolution of the MJO is currently quite limited. Zhang (2005) reported that 'many sophisticated models' are unable to produce an MJO signal at all, and those which do produce an eastward-propagating signal suffer from errors including the propagation being too weak or too fast, the spatial distribution and seasonal variation being unrealistic, and the wind field not being correctly coupled to convection. Indeed, the same review reported that dynamical models of the MJO tended to be no better than statistical models. More recent research still finds a lack of skill in simulating the MJO. For example, Lin et al. (2006) studied 14 (then) state-of-the-art GCMs which participated in the Fourth Assessment Report of the Intergovernmental Panel on Climate Change. They found that the intraseasonal variability in precipitation in the models tended to be too weak, only around half the models exhibited the required covectively-coupled equatorial waves - and those that did had phase speeds which were too large - and the ratio of eastward- to westward-propagating variance tended to be too small.

Many studies have suggested that the MJO acts to modulate the diurnal cycle. For example, Sui and Lau (1992) found that the diurnal cycle is diminished during the active phase of the MJO and enhanced during the suppressed phase, whilst Sui et al. (1997) found that diurnal cycles of atmospheric variations are more pronounced during the wet phase. Chen and Houze (1997) investigated the diurnal cycle of deep convection and found the suppressed MJO to be associated with small, short-lived cloud systems which form and decay in the afternoon, and the active MJO to be characterised by larger, longer-lived systems which form during the afternoon but do not peak until the early hours of the following morning, before decaying. Tian et al. (2006) and Suzuki (2009) found the diurnal cycle of deep convection over both land and ocean areas to be enhanced during the active MJO compared with the suppressed MJO, but the diurnal phase to be similar in both regimes. However, Rauniyar and Walsh (2011) suggested that the mean and diurnal maximum of rainfall rate is greatest during the suppressed MJO over land, but greatest during the active MJO over ocean. Oh et al. (2012) found in the western Maritime Continent that precipitation amount over land is the most suppressed and over ocean is the most active during the active phase of the MJO, in particular finding the precipitation to be more intense over the Java Sea in the morning and less intense over Borneo and Sumatra in the evening, relative to other stages of the MJO cycle. During the decaying phase of the MJO they found the precipitation to be significantly weakened over ocean but weakened only slightly over land.

The differences between the above studies suggest that further work is required before a consensus can be reached on the effects of the MJO on the diurnal cycle. Several (although not all) of these studies suffered from a lack of data (covering a fairly short range of time), or from compositing the diurnal cycle using data at a fairly coarse resolution. 
In this study we use 14 boreal winters (November to April) of high-resolution data to investigate how the diurnal cycle of precipitation changes throughout an MJO cycle, how synchronous certain variations are during the evolution of the MJO, and how these indicate scale interactions between the two cycles. We also consider the changes which occur as the atmospheric state evolves through each successive phase of the MJO, as opposed to simply comparing two separate regimes, 'active MJO' and 'suppressed MJO'.

Section 2 of this article contains information on the datasets used, and how they have been processed. In section 3, we present observations of the diurnal cycle of precipitation rate and the $\mathrm{MJO}$, and investigate how the diurnal amplitude is altered through the evolution of the MJO cycle. In section 4, we investigate variations and lag times during the MJO. Theoretical physical mechanisms responsible for our empirically found results are discussed in section 5; the results are summarized in section 6 along with a discussion of their implications for modelling.

\section{Data}

The Tropical Rainfall Measuring Mission (TRMM) (Simpson et al., 1996) 3B42 dataset provides surface precipitation rate $(r)$ estimates on a $0.25^{\circ}$ grid every $3 \mathrm{~h}$. The full dataset is created by the assimilation of microwave and infra-red satellite observations (Huffman et al., 2007). However, in this study we wish to compare precipitation with infra-red brightness temperature data (see below), so we use only the microwave ('high quality') part of 3B42, denoted 3B42HQ.

The TRMM satellite carries the Visible and InfraRed Scanner (VIRS), a five-channel radiometer (Kummerow et al., 1998). Radiances from channel 4 (central wavelength $10.826 \mu \mathrm{m}$, bandwidth $1.045 \mu \mathrm{m}$ ), gridded to a $0.5^{\circ}$ grid and converted to brightness temperatures $\left(T_{\mathrm{b}}\right)$ via a look-up table, are available as TRMM product 3G01. This study uses daily means of this dataset.

Using a combined field of outgoing long-wave radiation (OLR) and wind, Wheeler and Hendon (2004) (hereafter WH04) used empirical orthogonal function (EOF) analysis to define eight phases of the MJO. The amplitude and phase of the MJO on any given day is found from the principal components, known as RMM1 and RMM2, of the two leading EOFs.

The Global Land One-kilometer Base Elevation (GLOBE; GLOBE Task Team, 1999) dataset is a combination of several topography data sets on a 30 arc-second grid. For Figure 1, it was regridded to $0.11^{\circ}$ resolution.

Daily means of wind at $1000 \mathrm{hPa}$ and mean sea level pressure, both at $2.5^{\circ}$ horizontal resolution, are used from the National Center for Environmental Prediction-Department of the Environment (NCEP-DOE) Reanalysis 2 (Kanamitsu et al., 2002).

All climatologies in this article are based on boreal winters (November to April) - since this is when the MJO tends to be strongest - from 1998/99 to 2011/12 (14 winters). Climatologies for each WH04 phase exclude days on which the MJO was weak (i.e. when the amplitude $\left.\sqrt{(R M M 1)^{2}+(R M M 2)^{2}}<1\right)$.

All diurnal cycle analyses were composited based on their time in UTC which was then converted to local solar time (LST) by linear interpolation between time steps at each longitude.

\section{Interaction between the diurnal cycle and the MJO}

\subsection{Diurnal cycle in TRMM 3B42HQ precipitation}

Figure 2 shows the climatology of the diurnal cycle of precipitation from TRMM 3B42HQ precipitation rate
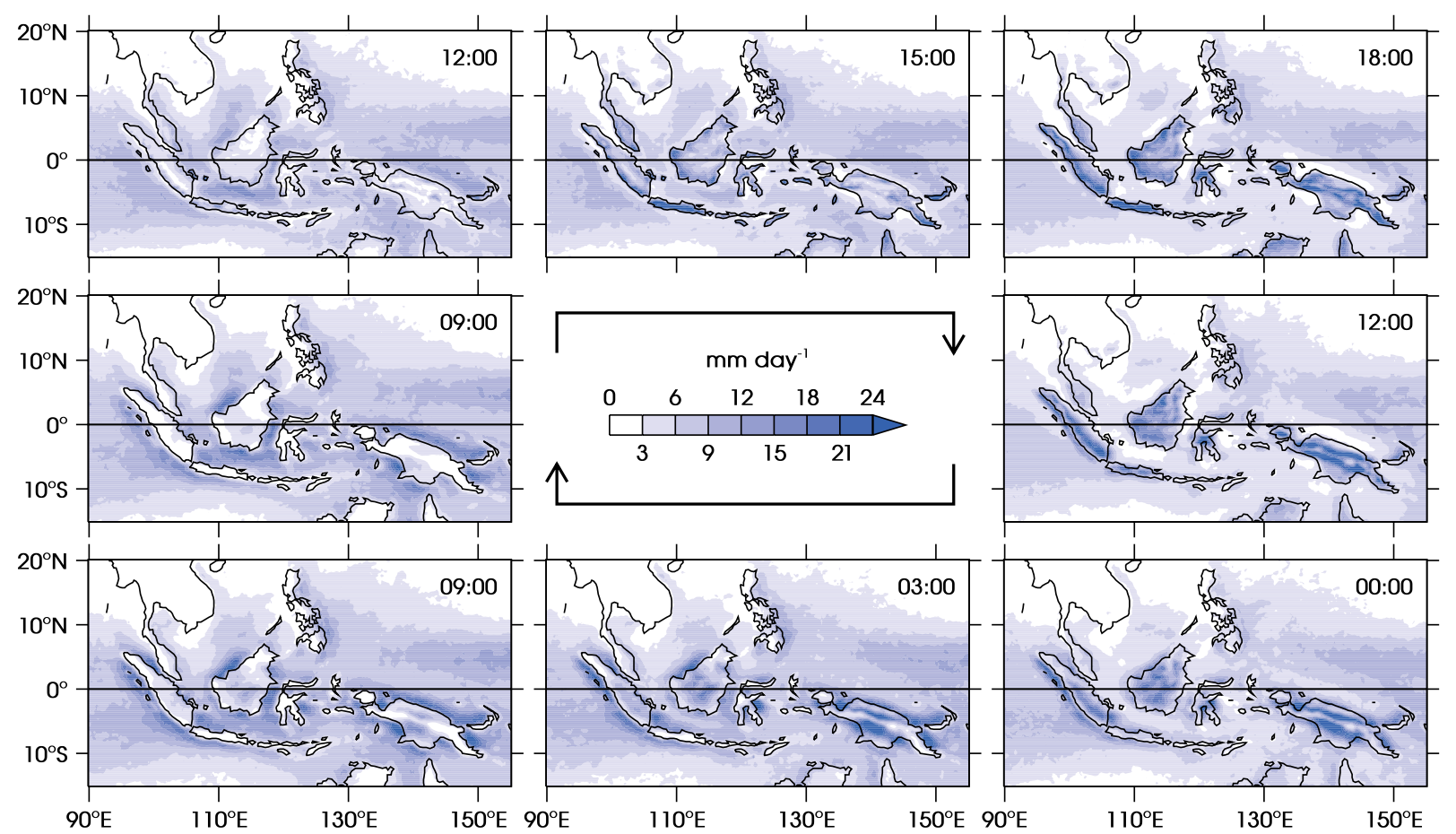

Figure 2. Climatological diurnal cycle of precipitation rate from TRMM 3B42HQ for November to April, 1998/99 to 2011/12. Time of day is given in local solar time for all longitudes, and moves forward in the clockwise direction round the diagram. This figure is available in colour online at wileyonlinelibrary.com/journal/qj 


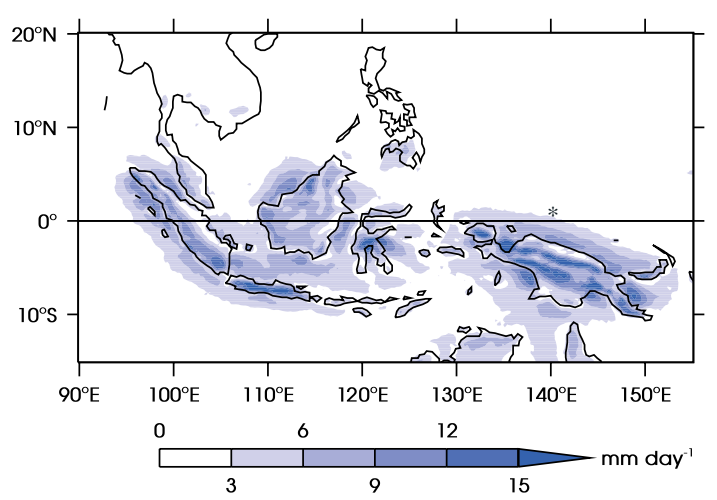

Figure 3. Climatological amplitude of the diurnal harmonic of precipitation rate from TRMM 3B42HQ. This figure is available in colour online at wileyonlinelibrary.com/journal/qj

estimates, with the time of day moving clockwise around the diagram. Figure 3 shows the climatological amplitude of the diurnal harmonic $\left(r_{\mathrm{d}}\right)$ of precipitation rate, calculated for each grid point from the eight maps in Figure 2. It was explained in section 1 how the strong land-based diurnal cycle arises from the relative effects of insolation over land and sea. The effect of convective rainfall being focused over land is enhanced by local effects such as orographic rainfall (Qian, 2008); by comparison of Figures 1 and 3 it can be seen that in many areas there is an especially strong diurnal cycle associated with high topography, such as along the islands of Sumatra and Java, in central Sulawesi and northwest Borneo, and along both sides of the high mountain range running east-west along New Guinea.

The diurnal cycle of precipitation rate estimates over the ocean is consistently weaker than over most of the land, since the water warms relatively slowly, but over the oceans between and around the Maritime Continent islands there is a much stronger diurnal cycle than in the open eastern Indian and western Pacific Oceans. Figure 2 shows that the diurnal cycle over some of the oceanic regions close to the Maritime Continent coastlines is due in part to the overnight offshore propagation of precipitation from the islands (Mori et al., 2004) (for example, to the southwest of Sumatra, to the northwest of Borneo and to the north of New Guinea). It should be noted that this effect is due not to the advection of storm clouds offshore, but to the triggering of gravity waves over the land which create new convection as they propagate away from their point of initiation (Love et al., 2011).

\subsection{MJO in TRMM OLR and precipitation}

The MJO is composited, for each WH04 MJO phase, for daily mean brightness temperature $\bar{T}_{\mathrm{b}}$ (Figure 4 , from TRMM 3G01, which is derived from OLR) and daily mean precipitation rate $\bar{r}$ (Figure 5, from TRMM 3B42HQ). Figure 4 shows the active convective envelope (lower temperatures correspond to higher cloud tops, which are associated with larger deep convective systems) propagating slowly eastwards, with the suppressed envelope behind it. The active MJO envelope as measured with $\bar{T}_{\mathrm{b}}$ appears over the Maritime Continent region during WH04 phases 3 to 6 , especially in phases 4 and 5 (compare with Figures 7 and 8 of WH04). The maps show a large degree of spatial coherence.

During certain WH04 phases there are some regions within the MJO envelope where the anomaly is small or even of the opposite sign from its immediate surroundings.
These regions are often, but not exclusively, over land. For example, over west Borneo in phases 1 and 5, and over New Guinea in phases $1-2$ and $4-6$, the anomaly is small; and over south New Guinea in phase 3 the anomaly is of the opposite sign to the rest of the envelope.

For $\bar{r}$ in Figure 5 the synoptic picture is similar to that for $\bar{T}_{\mathrm{b}}$, with a clear eastward propagation of successive active and suppressed envelopes, but there is more variability on small spatial scales. In particular, during WH04 phase 1 the large-scale MJO envelope over the Maritime Continent shows suppressed conditions, but there are near-zero or even positive precipitation anomalies over Sumatra, western Borneo and New Guinea. In phase 2, the active MJO has now reached the western Maritime Continent and subsumed the existing wet conditions over Sumatra into the large-scale envelope. However, western Borneo, Sulawesi and southern New Guinea show active convection, whilst being embedded in the large-scale envelope of suppressed conditions. Later in the MJO cycle these islands experience negative rainfall anomalies while the surrounding envelope is in its active phases (5-6). Each of these regions is a case of a vanguard of the propagating MJO precipitation 'leaping ahead' of the main MJO envelope. This leaping ahead is a characteristic of the MJO propagation which is peculiar to the archipelago of the Maritime Continent.

\subsection{Modulation of the diurnal cycle by the MJO}

We now consider the effect of the MJO on the diurnal cycle of precipitation rate

$$
r=\bar{r}+r_{\mathrm{d}} \cos \left\{\frac{2 \pi}{\tau}\left(t-t_{0}\right)\right\},
$$

where $\tau=24 \mathrm{~h}$ is the time period of the diurnal harmonic and $t_{0}$ is a time offset. We are especially interested in whether it is only the daily mean precipitation $\bar{r}$ which is dependent on the phase of the MJO, or whether the amplitude of the diurnal harmonic $r_{\mathrm{d}}$ is also modulated.

As an example, the diurnal cycle averaged over the land area of Borneo is plotted in Figure 6; the climatology is shown along with the opposing WH04 phases 3 and 7 . The daily mean is greater during the wetter, more active phase (3) and lesser during the drier, more suppressed phase (7), as we already know from Figure 5. In addition, the diurnal amplitude is enhanced during the wetter phase and diminished during the drier phase. Hence, there is an interaction by which the small-scale diurnal cycle is modulated by the state of the large-scale MJO envelope.

The climatological mean amplitude $r_{\mathrm{d}}$ of the diurnal harmonic, averaged over all days in the study period, calculated for each grid point was shown in Figure 3. The mean amplitude at each grid point is also calculated using just the days in a particular WH04 phase; a map of the anomalous amplitude of the diurnal harmonic is then calculated for each WH04 phase (Figure 7) by subtracting the mean over all WH04 phases. These $r_{\mathrm{d}}$ anomalies are of the same order of magnitude as the $\bar{r}$ anomalies in Figure 5 (note that both figures use the same shading scale). There is not a smooth eastward propagation over the Maritime Continent, but $r_{\mathrm{d}}$ exhibits strong anomalies which are confined to the islands and immediately-surrounding ocean. This notably includes but is not confined to those ocean regions where there is strong offshore propagation, such as southwest of 

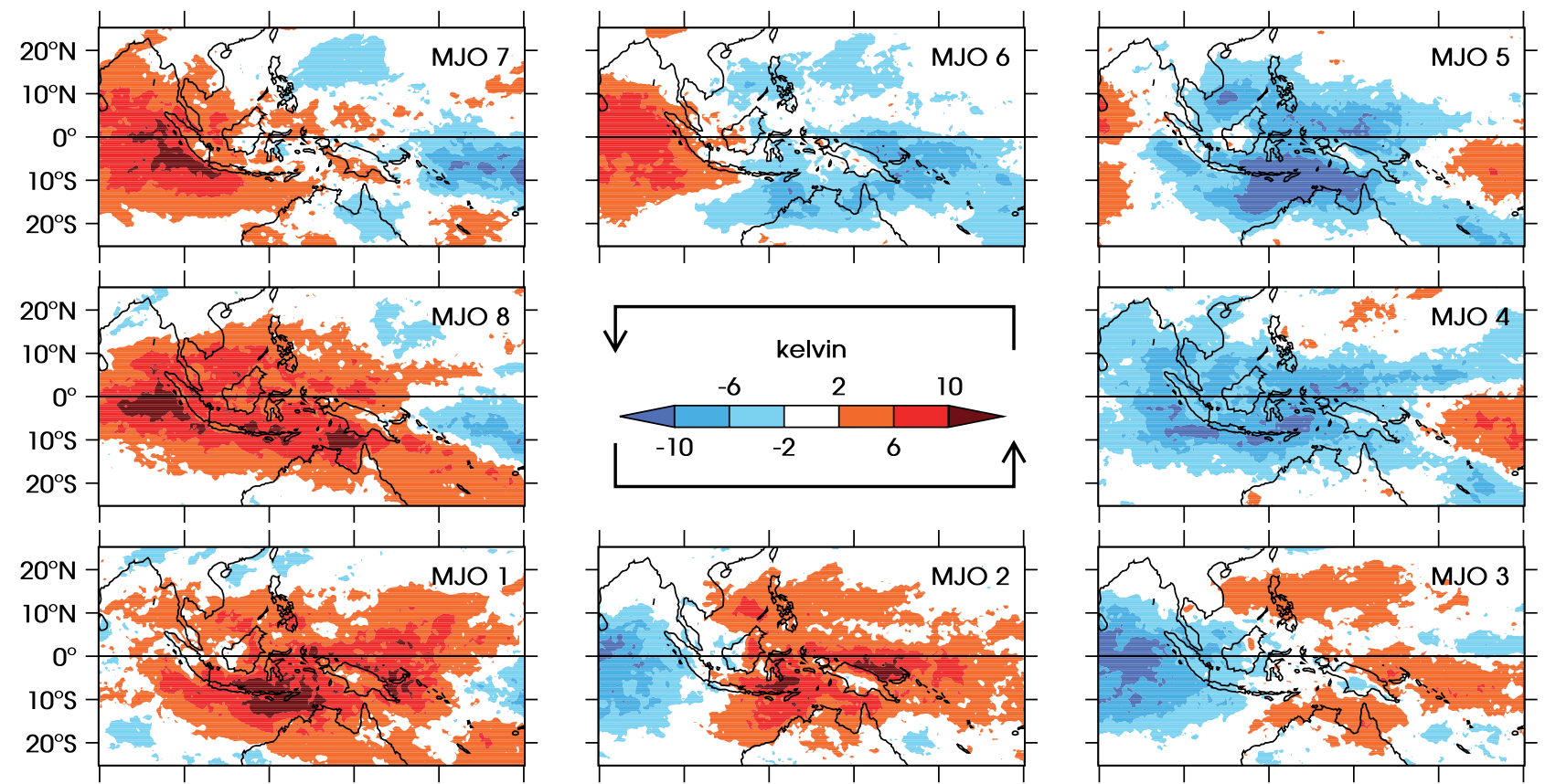

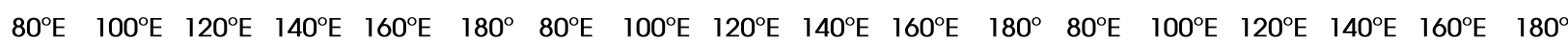

Figure 4. Daily mean brightness temperature anomaly from TRMM $3 \mathrm{G} 01$ for each phase of the MJO as defined by Wheeler and Hendon (2004). Phases move forward in time in the anti-clockwise direction round the diagram. This figure is available in colour online at wileyonlinelibrary.com/journal/qj
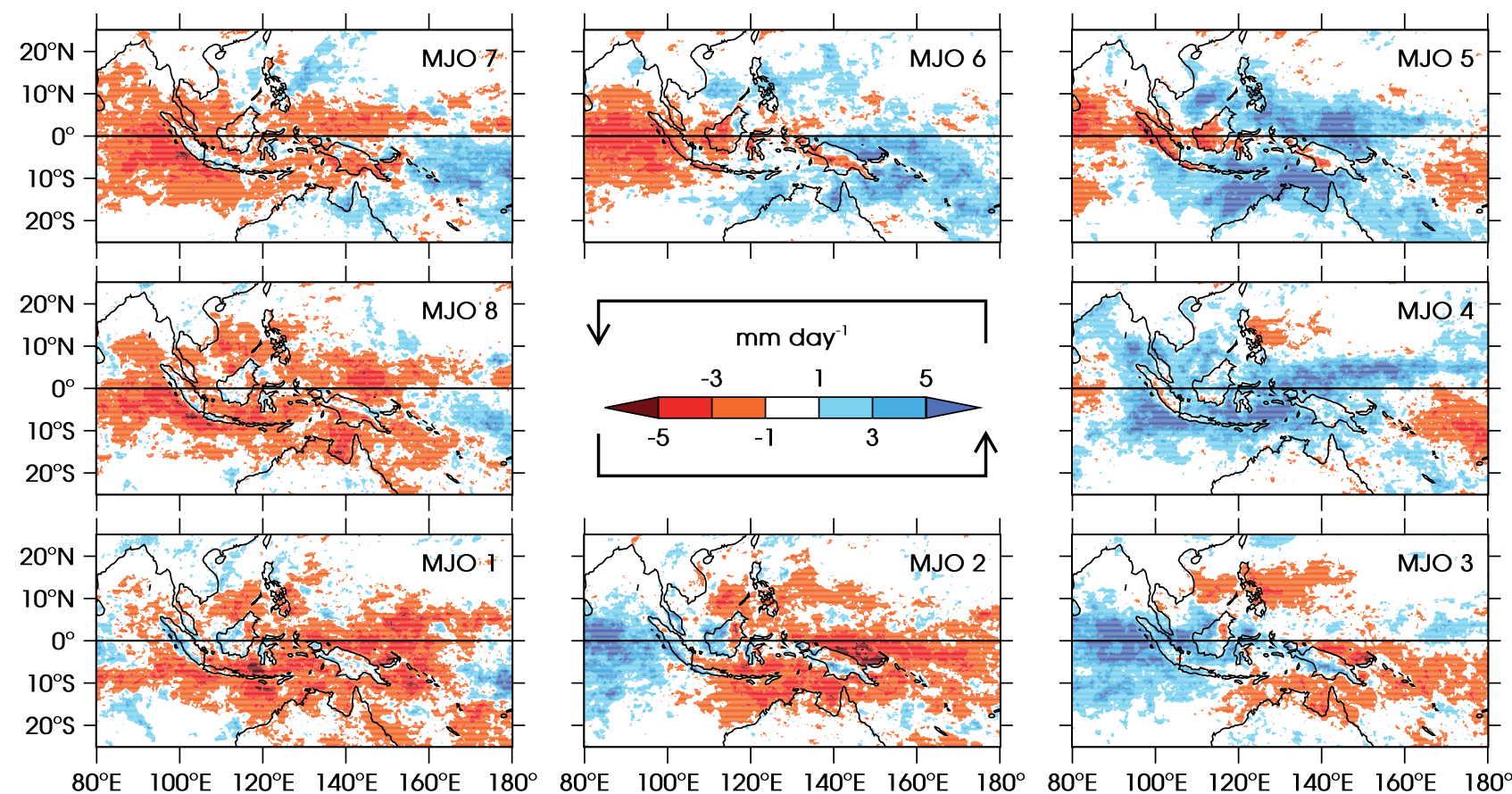

Figure 5. As Figure 4, but for daily mean precipitation anomaly from TRMM 3B42HQ. This figure is available in colour online at wileyonlinelibrary.com/journal/qj

Sumatra and north of New Guinea (Figure 2). The negative anomalies off the north coast of New Guinea in phases 1-3 and off the south coast in phases 5-7 confirm the findings of Ichikawa and Yasunari (2008), who showed how the propagation of precipitation is altered by the wind anomaly associated with the MJO.

The $r_{\mathrm{d}}$ anomalies differ by as much as $10 \mathrm{~mm} \mathrm{day}^{-1}$ in opposing MJO phases over some regions. There is spatial coherence, but on a scale smaller than the MJO envelope, unlike in the $\bar{T}_{\mathrm{b}}$ and $\bar{r}$ anomalies; the MJO envelope appears not to modulate the diurnal cycle in a simple, linear way.
Although we saw in Figure 3 that the diurnal cycle tends to be strongest near to high topography, there is not a clear correlation between topography (Figure 1) and $r_{\mathrm{d}}$ anomaly (Figure 7), so it appears that, while topography is important in determining the strength of the diurnal cycle, it has little effect on the degree to which the diurnal cycle is modulated by the MJO.

For each grid point in Figures 5 and 7, there is a notional scatter plot with one point for each WH04 phase, with the daily mean precipitation rate as the abscissa and the diurnal amplitude of precipitation rate as the ordinate. The scatter 


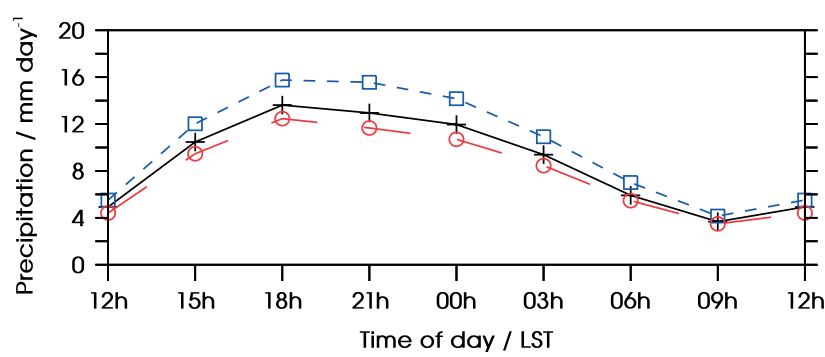

Figure 6. Diurnal cycle of land-mean precipitation $r\left(\mathrm{~mm} \mathrm{day}^{-1}\right)$ over Borneo: climatology (solid black with crosses) has $\bar{r}=9.1, r_{\mathrm{d}}=6.3$; MJO phase 3 (short-dashed with squares) has $\bar{r}=10.6, r_{\mathrm{d}}=8.0$; MJO phase 7 (long-dashed with circles) has $\bar{r}=8.3, r_{\mathrm{d}}=5.7$. This figure is available in colour online at wileyonlinelibrary.com/journal/qj

plot for three arbitrary points, chosen as examples, is shown in Figure 8. Linear regression was computed for each grid point; the linear fit is also shown in Figure 8. The gradient and correlation coefficient $R$ for all grid points are shown in Figures 9 (a) and (b) respectively.

Statistical significance of the correlation is calculated using a Fisher $Z$ transform of the correlation coefficient (Wilks, 2011; p 183). With a null hypothesis of zero correlation between the amplitude $r_{\mathrm{d}}$ of the diurnal harmonic of precipitation and the daily mean precipitation $\bar{r}$ within each WH04 phase, $Z$ follows a Student's $t$ distribution with zero mean and variance $(n-3)^{-1}$, where $n=8$ is the number of paired data points. For significance at the $95 \%$ level, the critical value of the correlation coefficient for rejection of the null hypothesis is $\tanh (2.31 \sigma)=\tanh (2.31 / \sqrt{5})=0.78$.

In Figure 9(b), over regions where the diurnal cycle is strong (where the amplitude of the diurnal harmonic exceeds $10 \mathrm{~mm} \mathrm{day}^{-1}$; Figure 3 ), the mean of $R$ is 0.90 , which is above the $95 \%$ significance threshold of 0.78 . $R=0.90$ corresponds to a correlation with $99 \%$ confidence and $R^{2}=81 \%$ of the variance in the MJO daily mean precipitation anomaly being accounted for by the change in the diurnal cycle. Over these same regions the mean of the gradient between $r_{\mathrm{d}}$ and $\bar{r}$ is $1.18(\approx 1)$, so they are of similar magnitude. We know from Figure 5 that the MJO causes the variation in daily mean precipitation. Therefore, we suggest that where there is a strong diurnal cycle, the change in the amplitude of the diurnal cycle is the dominant contributor to the daily mean MJO precipitation. Thus, the MJO precipitation in those regions is largely due to the diurnal cycle. This hypothesis will be examined further in section 4 below.

\section{Relative MJO phases}

We now consider the extent to which brightness temperature $\bar{T}_{\mathrm{b}}$, daily mean precipitation $\bar{r}$ and amplitude of the diurnal cycle $r_{\mathrm{d}}$ lead or lag each other during an MJO cycle. We take two approaches: first (section 4.1) we examine when the maxima in $\bar{r}$ and $r_{\mathrm{d}}$ occur relative to the largescale $\bar{T}_{\mathrm{b}}$ envelope; second (section 4.2 ) we construct 'MJO harmonics' and use them to compare locally (i.e. at each grid point) the timings of the maxima in $\bar{T}_{\mathrm{b}}, \bar{r}$ and $r_{\mathrm{d}}$.

\subsection{MJO phase relative to the large-scale envelope}

Figure 10 shows the land-means and ocean-means of $\bar{T}_{\mathrm{b}}$, $\bar{r}$ and $r_{\mathrm{d}}$ over the region $7^{\circ} \mathrm{S}-10^{\circ} \mathrm{N}, 100-120^{\circ} \mathrm{E}$ (most of Sumatra and Borneo). The bold solid black line indicates the $\bar{T}_{\mathrm{b}}$ signal over ocean, which may be thought of as the large-scale MJO envelope unaltered by the presence of the Maritime Continent islands. The narrower solid black line ( $\bar{T}_{\mathrm{b}}$ over land) follows roughly the same shape as the oceanmean line but at a lower brightness temperature, as expected since convective precipitation is focused over the islands.
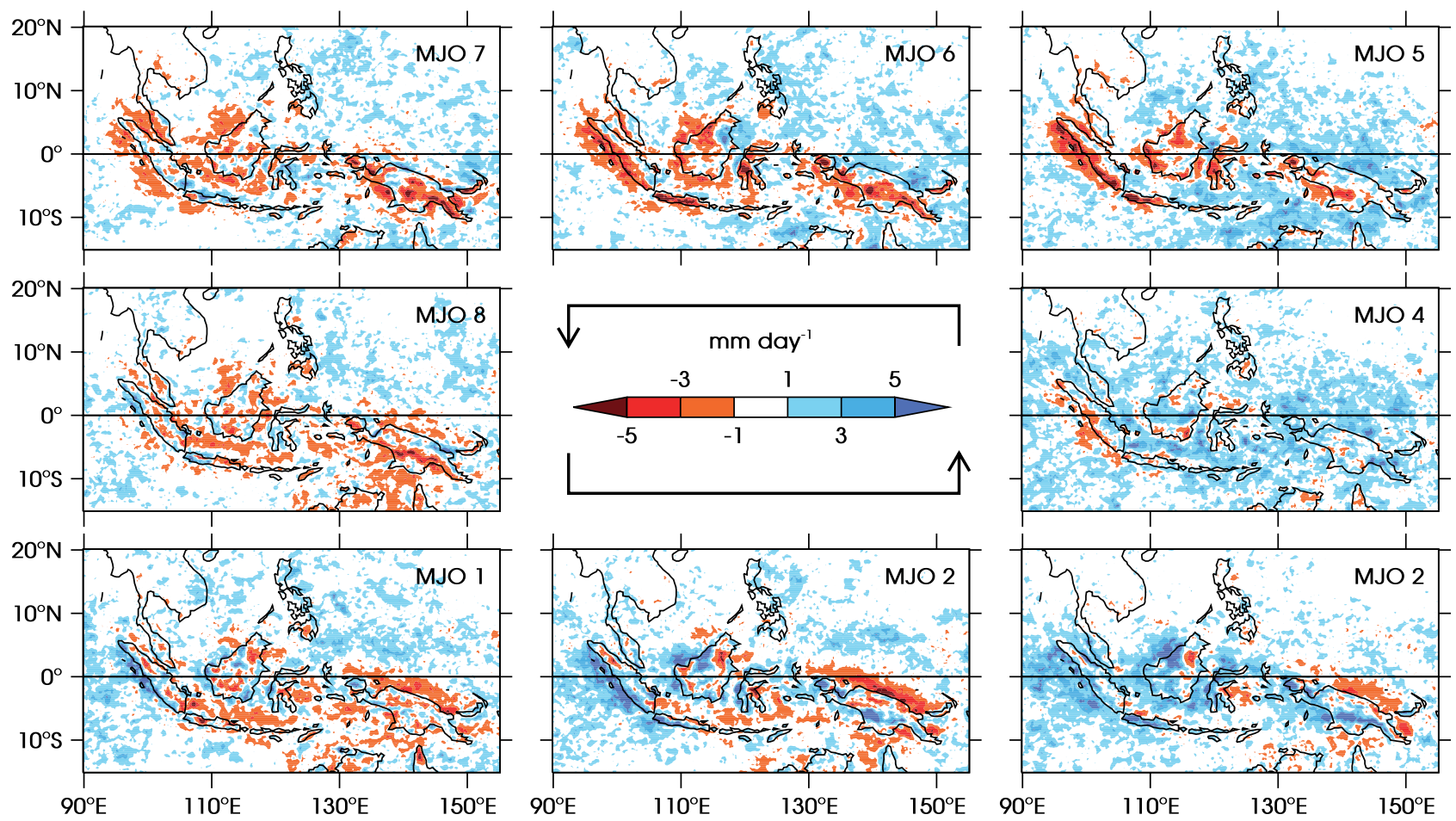

Figure 7. Anomaly of the amplitude $r_{\mathrm{d}}$ of the diurnal harmonic of precipitation from TRMM 3B42HQ in each phase of the MJO. This figure is available in colour online at wileyonlinelibrary.com/journal/qj 


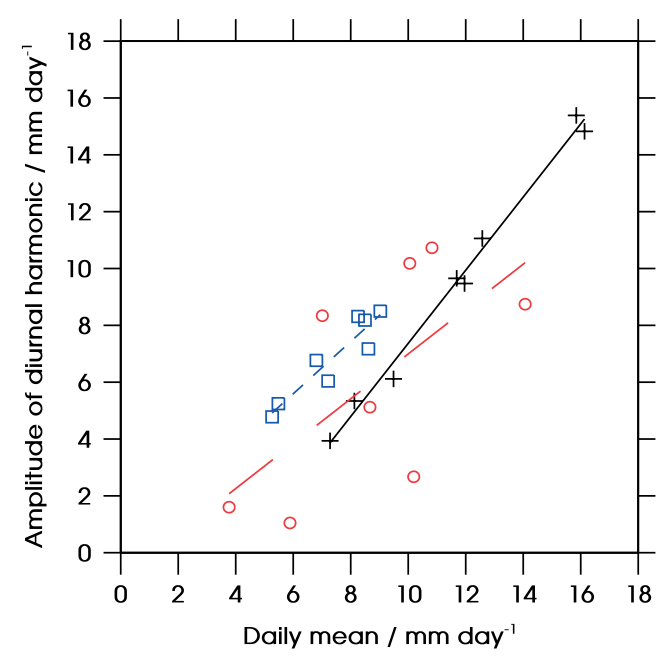

Figure 8. Scatterplot of the amplitude of the diurnal harmonic of precipitation against daily mean precipitation for the eight WH04 phases, for the three sample points $2.125^{\circ} \mathrm{N}, 113.125^{\circ} \mathrm{E}$ (Borneo; crosses and solid line), $5.125^{\circ} \mathrm{S}, 142.125^{\circ} \mathrm{E}$ (New Guinea; squares and short-dashed line), and $0.125^{\circ} \mathrm{N}, 103.125^{\circ} \mathrm{E}$ (Sumatra; circles and long-dashed line). Straight lines indicate the best fit according to linear regression; the gradient and correlation coefficient for all grid points are shown in Figure 9. This figure is available in colour online at wileyonlinelibrary.com/journal/qj

(a)
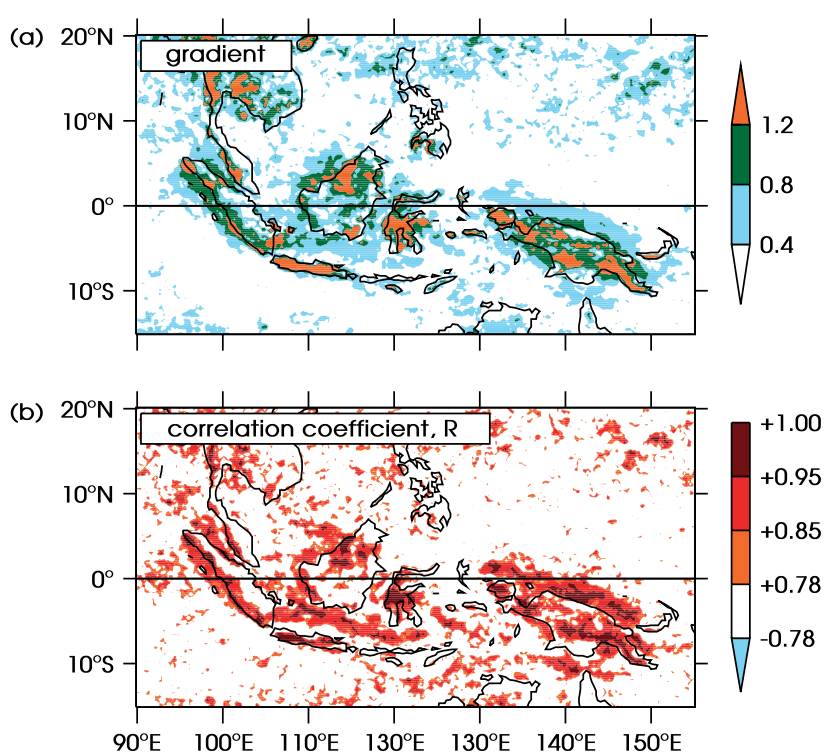

Figure 9. (a) Gradient and (b) correlation coefficient $R$ of the linear relationship between the amplitude of the diurnal harmonic of precipitation for each MJO phase, and the daily mean precipitation in the corresponding MJO phase (both from TRMM 3B42HQ). (Figure 8 shows three example grid points.) In (b), regions in white are below the $95 \%$ confidence threshold of $|R|=0.78$. This figure is available in colour online at wileyonlinelibrary.com/journal/qj

The $\bar{T}_{\mathrm{b}}$ signal peaks in WH04 phase 4 over both land and ocean, but the daily mean precipitation over land peaks earlier in WH04 phase 3. The diurnal amplitude of precipitation $r_{\mathrm{d}}$ over the land also peaks in phase 3 and follows the $\bar{r}$ signal throughout the whole MJO. Hence, the $\bar{r}$ and $r_{\mathrm{d}}$ signals associated with the MJO peak ahead of the large-scale $\bar{T}_{\mathrm{b}}$ envelope by approximately one WH04 phase, or 1/8 of a cycle. We have already seen in Figure 9(a) that there is an approximate 1:1 relationship between $\bar{r}$ and $r_{\mathrm{d}}$, and in 9(b) that most of the MJO-variance in $\bar{r}$ may be attributed to the changes in $r_{\mathrm{d}}$. This suggests that the strong diurnal cycle, leading the large-scale MJO envelope,

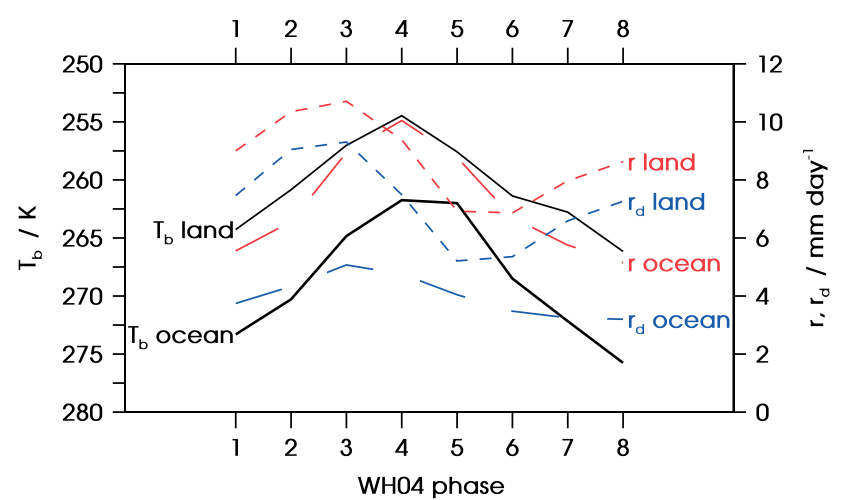

Figure 10. Means of $\bar{T}_{\mathrm{b}}$ (from TRMM 3G01), $\bar{r}$ and $r_{\mathrm{d}}$ (both from TRMM $3 \mathrm{~B} 42 \mathrm{HQ})$, all averaged separately over land and ocean, for the region $7^{\circ} \mathrm{S}-10^{\circ} \mathrm{N}, 100-120^{\circ} \mathrm{E}$ (most of Sumatra and Borneo), plotted against WH04 phase. Note that the brightness temperature axis is inverted. The GLOBE dataset (Figure 1) was used as the land mask. Solid black lines show $\bar{T}_{\mathrm{b}}$ (bold for ocean, thin for land); dashed lines show $\bar{r}$ and $r_{\mathrm{d}}$ (long-dashed for ocean, short-dashed for land). This figure is available in colour online at wileyonlinelibrary.com/journal/qj

is mostly responsible for the daily mean signal also leading the envelope.

In contrast, over the ocean $\bar{r}$ is roughly in phase with $\bar{T}_{\mathrm{b}}$. This may be attributed to the fact that the ocean-based diurnal cycle is weak (Figure 3), so even though it does peak ahead of $\bar{T}_{\mathrm{b}}$ its contribution to the daily main precipitation is insufficient to cause $\bar{r}$ to leap ahead of the MJO envelope. For both land and ocean the situation over New Guinea is very similar (not shown).

\subsection{Phase of the MJO harmonics}

We now introduce MJO harmonics, which will be used to quantify MJO phase lags at each grid point. We create separate climatologies for each of the eight WH04 phases for some variable, just as in Figures 4, 5 and 7. These eight maps form a time series, since they describe successive phases of the MJO cycle. We compute harmonics of this time series for each grid point, referring to the fundamental harmonic as the 'MJO harmonic'. The amplitude of the MJO harmonic describes how much the variable in question changes as the MJO evolves while the phase of the MJO harmonic ( $\phi_{\mathrm{WH} 04}$, measured in WH04 phases) tells us the stage of the $\mathrm{MJO}$ at which the maximum value of the variable occurs, where the $\mathrm{MJO}$ is now modelled as a single, pure sine wave. The phase of the MJO harmonic is not required to be an integer value; it varies continuously in the range $0.5 \leq \phi_{\mathrm{WH} 04} \leq 8.5$, and the phase is periodic so these end points are equivalent. The amplitudes of the semi-MJO and higher-frequency harmonics were always found to be much smaller than the amplitude of the MJO harmonic (not shown here). Note that this technique is an alternative to the approach of Sperber et al. (1997), in which the eastward propagation of the active MJO was plotted by picking out for each grid point, from lagged correlation maps, the day on which there is the strongest correlation between the data and a previously computed MJO index.

For example, the phase of the MJO harmonic of negative brightness temperature $\left(\phi_{\mathrm{WH} 04}\left(-\bar{T}_{\mathrm{b}}\right)\right.$; Figure 11(a)) shows when the MJO is most active, since negative $\bar{T}_{\mathrm{b}}$ anomalies correspond to enhanced convection. There is a progression of the active MJO envelope from west to east, as seen earlier 

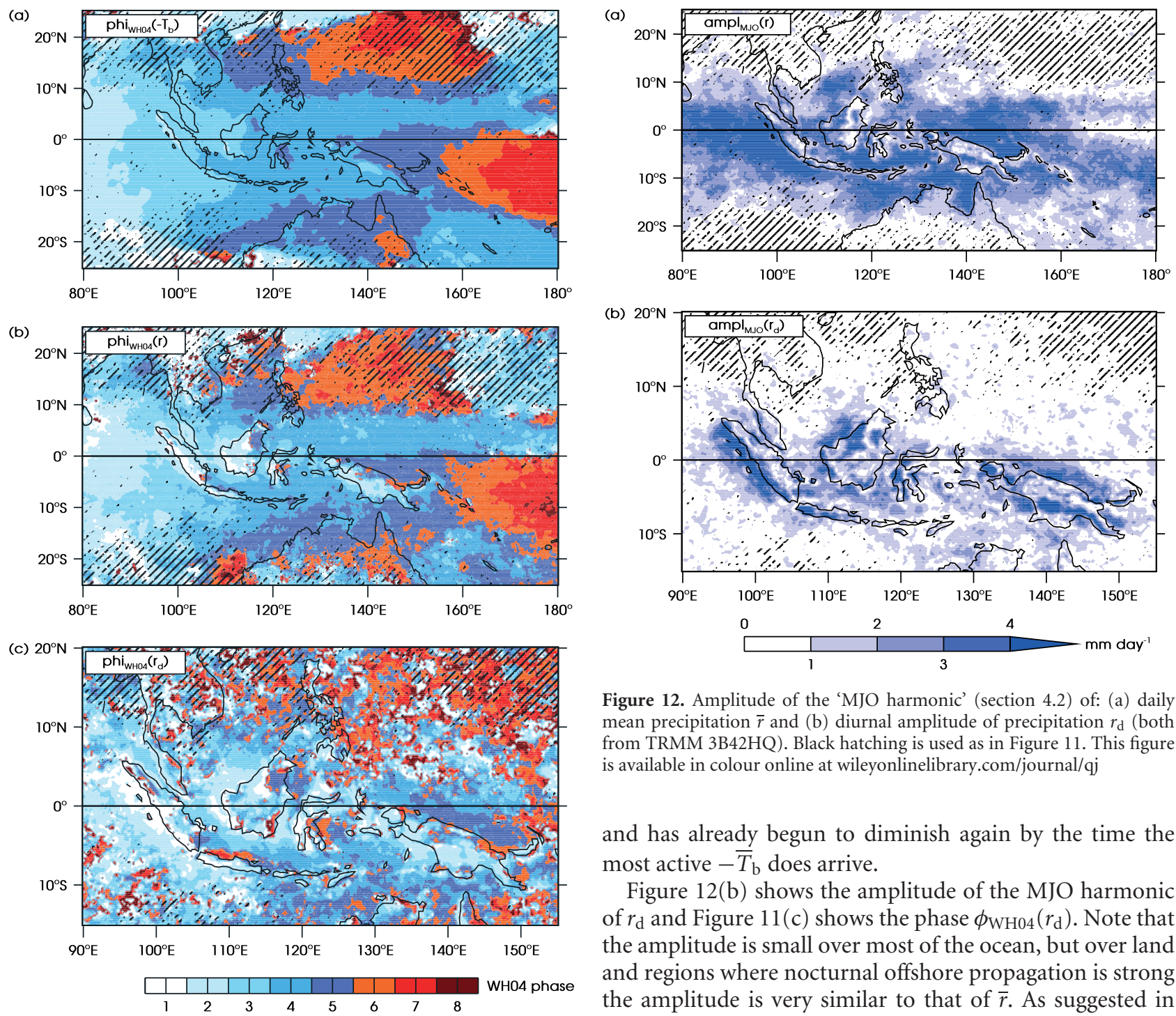

Figure 11. Phase of the 'MJO harmonic' (section 4.2) of: (a) daily mean negative brightness temperature $-\bar{T}_{\mathrm{b}}$ (from TRMM 3G01); (b) daily mean precipitation $\bar{r}$ (from TRMM 3B42HQ); (c) diurnal amplitude of precipitation $r_{\mathrm{d}}$ (also from TRMM 3B42HQ). The phase is measured in MJO phases as defined by Wheeler and Hendon (2004). Black hatching indicate regions of low variability of the diurnal cycle during the MJO, defined as the anomaly in Figure 7 being $<1 \mathrm{~mm} \mathrm{day}^{-1}$ for all eight WH04 phases. This figure is available in colour online at wileyonlinelibrary.com/journal/qj

in Figure 4. The MJO is most active over the Maritime Continent during phases 3 to 5 . The intertropical convergence zone (ITCZ) and South Pacific convergence zone (SPCZ) extend eastwards and southeastwards respectively from the centre of the Maritime Continent region, and are visible here since they are most active ahead of when their immediate surroundings are most active.

The amplitude of the MJO harmonic of $\bar{r}$ is shown in Figure 12(a) and the phase of the harmonic in Figure 11(b). The amplitude of the variation in $\bar{r}$ is generally large over the ocean within the Maritime Continent; over land it tends to be small except for regions where the diurnal cycle is strong (Figure 3). $\bar{r}$ generally has the same WH04 phase as $-\bar{T}_{\mathrm{b}}$ to the west of the Maritime Continent, but over the major islands such as Sumatra, Borneo and New Guinea $\bar{r}$ tends to peak earlier than $-\bar{T}_{\mathrm{b}}$ in the MJO. Thus, the precipitation appears to leap ahead of the brightness temperature signal,

Figure 12. Amplitude of the 'MJO harmonic' (section 4.2) of: (a) daily mean precipitation $\bar{r}$ and (b) diurnal amplitude of precipitation $r_{\mathrm{d}}$ (both from TRMM 3B42HQ). Black hatching is used as in Figure 11. This figure is available in colour online at wileyonlinelibrary.com/journal/qj

and has already begun to diminish again by the time the most active $-\bar{T}_{\mathrm{b}}$ does arrive.

Figure 12(b) shows the amplitude of the MJO harmonic of $r_{\mathrm{d}}$ and Figure 11(c) shows the phase $\phi_{\mathrm{WH} 04}\left(r_{\mathrm{d}}\right)$. Note that the amplitude is small over most of the ocean, but over land and regions where nocturnal offshore propagation is strong the amplitude is very similar to that of $\bar{r}$. As suggested in section 3.3 in reference to Figure 7, there is no clear eastward propagation, as there is for $\phi_{\mathrm{WH} 04}\left(-\bar{T}_{\mathrm{b}}\right)$ and $\phi_{\mathrm{WH} 04}(\bar{r})$. A visual comparison of Figures 11(b) and (c) shows that $\bar{r}$ and $r_{\mathrm{d}}$ tend to have the same WH04 phase over the land of the Maritime Continent. Although $\phi_{\mathrm{WH} 04}\left(r_{\mathrm{d}}\right)$ shows much less spatial coherence than Figures 11(a) and (b) in some regions, the spatial coherence is still strong over and around the land, which is where the diurnal cycle is strongest (Figure 3).

As an improvement on the qualitative comparisons of $\phi_{\mathrm{WH} 04}$ made above, we can quantify relative MJO phases. For example, if variable $X$ has its maximum at WH04 phase 4.0 and variable $Y$ has its maximum at $\mathrm{WH} 04$ phase 6.0, we define the MJO phase lag of $Y$ relative to $X$ as

$$
\Delta \phi(X, Y)=\phi_{\mathrm{WH} 04}(Y)-\phi_{\mathrm{WH} 04}(X)=+2.0 .
$$

That is, $Y$ lags $X$ by two WH04 phases or a quarter of an MJO cycle.

Over most of the ocean, $-\bar{T}_{\mathrm{b}}$ and $\bar{r}$ are in phase through the MJO cycle, since $\Delta \phi\left(-\bar{T}_{\mathrm{b}}, \bar{r}\right) \approx 0$ (Figure $\left.13(\mathrm{a})\right)$. This supports the canonical view that OLR is a good proxy for precipitation. The exception over ocean is the ITCZ at about $5^{\circ} \mathrm{N}$, extending from $135^{\circ} \mathrm{E}$ to the eastern edge of the domain, where $\Delta \phi \approx-1$ so $\bar{r}$ leads $-\bar{T}_{\mathrm{b}}$ by about one WH04 phase. Over the islands of the Maritime Continent, $\Delta \phi\left(-\bar{T}_{\mathrm{b}}, \bar{r}\right)$ is also approximately -1 almost everywhere. Hence, over the land, where the diurnal cycle is strong, the view that 
(a)

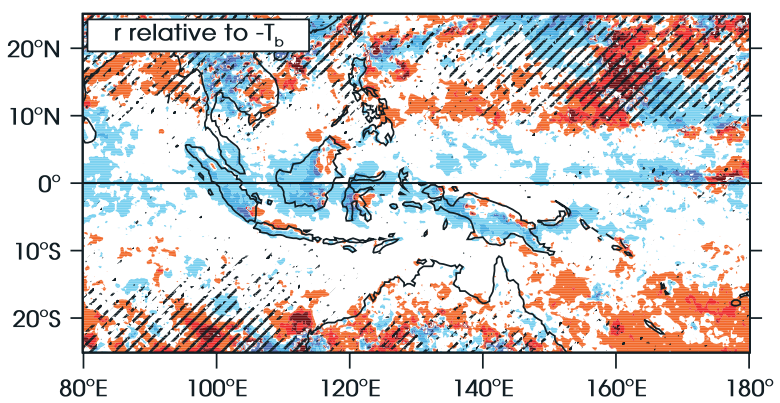

(b) $20^{\circ} \mathrm{N}$

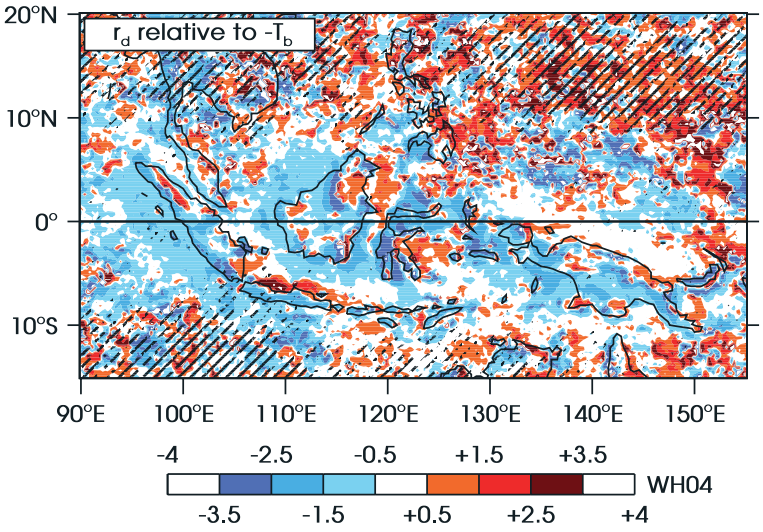

Figure 13. MJO phase lags (section 4.2): (a) $\Delta \phi\left(-\bar{T}_{\mathrm{b}}, \bar{r}\right)$ (i.e. Figure 11(b) minus 11(a)), and (b) $\Delta \phi\left(-\bar{T}_{\mathrm{b}}, r_{\mathrm{d}}\right)$ (i.e. Figure 11(c) minus 11(a)). As in Figure 11, the scale is measured in MJO phases as defined by Wheeler and Hendon (2004). If $\Delta \phi\left(-\bar{T}_{\mathrm{b}}, \bar{r}\right)$ is positive (negative) then the maximum in $\bar{r}$ lags (leads) the maximum in $-\bar{T}_{\mathrm{b}}$, and similarly for other variables. Black hatching is used as in Figure 11. This figure is available in colour online at wileyonlinelibrary.com/journal/qj

OLR is a good proxy for precipitation begins to break down. The daily mean precipitation again occurs about one WH04 phase (one eighth of an MJO cycle, typically about 6 days) ahead of when the most active MJO envelope arrives as observed in infra-red brightness temperature.

We now compare this picture with that of $\Delta \phi\left(-\bar{T}_{\mathrm{b}}, r_{\mathrm{d}}\right)$ in Figure 13(b). As suggested in the discussion above of Figures 11(b) and (c), there is a strong similarity between the WH04 phase of $\bar{r}$ and $r_{\mathrm{d}}$ over the land of the Maritime Continent; we see here that both tend to lead $-\bar{T}_{\mathrm{b}}$ by about one WH04 phase, for example over the southwest coast of Sumatra and the whole southern half of that island, all but the east of Borneo, and most of New Guinea. Over the ocean, far from land, the diurnal cycle is weak and changes to it during the MJO tend to be incoherent.

\section{Discussion}

In the previous section we compared the relative MJO phases of $\bar{T}_{\mathrm{b}}, \bar{r}$ and $r_{\mathrm{d}}$, and found that in the Maritime Continent the land-based precipitation signals jump ahead of the normal large-scale MJO envelope (section 4.1), and the precipitation signals over land jump ahead of the OLR signal over land, so that OLR can no longer be considered a good proxy for rainfall (section 4.2). We now consider possible mechanisms for these phenomena.

\subsection{Why does the diurnal cycle lead the main MJO envelope?}

We have seen that the diurnal cycle is strongest over land about 1/8 of an MJO cycle (about six days or, equivalently,
$2000 \mathrm{~km}$ ) ahead of the arrival of the active MJO envelope. The land diurnal cycle is set up by a land-sea temperature contrast as insolation heats the land and water at unequal rates (section 3.1). It is during the active phase of the MJO that the sky is the most cloudy, so incoming solar radiation flux at the surface is at a minimum. One possible mechanism which suggests itself for the observed MJO phase lag is that during the active phase of the MJO the diurnal cycle is suppressed slightly by the low level of insolation, and that the diurnal cycle precedes the most active part of the MJO because that is when the balance between convective activity and cloudiness allows the strongest over-land convection to occur. However, were this the case, we would expect to see a double peak in the diurnal amplitude, with one peak before the most active MJO and one after it. Note that evidence for such a double peak exists for other variables, for example latent heat flux from the ocean (Batstone et al., 2005). There is no evidence for such a double peak in the diurnal amplitude anomalies in Figure 7, and the fact that the 'semi-MJO harmonic' and all higher-frequency harmonics have relatively small amplitudes (as mentioned in section 4) suggests that the diurnal amplitude anomalies are roughly sinusoidal with only one peak and one trough per MJO cycle. Therefore, this simple scheme fails to predict the observed MJO phase lags between $-\bar{T}_{\mathrm{b}}, \bar{r}$ and $r_{\mathrm{d}}$.

The regions of anomalous convection in the MJO propagate eastwards not by advection of the numerous convective systems therein but by priming the atmosphere to the east for further convection and shutting off convection to the west. The fact that the land-based Maritime Continent diurnal cycle peaks just to the east of the active MJO envelope but not to the west of it suggests that the diurnal cycle is being excited as part of the eastward-propagation mechanism of the MJO. There are existing theories of the propagation of the MJO based on large-scale equatorial wave dynamics (e.g. Hendon and Salby, 1994; Maloney and Hartmann, 1998; Matthews, 2000). We now propose a mechanism that is consistent with both our observations and these previously proposed mechanisms.

\subsection{MJO propagation and diurnal cycle excitation by equatorial wave dynamics}

Figure 14 shows the anomalies in WH04 phase 2 of (a) mean sea level pressure, (b) wind at $1000 \mathrm{hPa}$ and (c) horizontal divergence at $1000 \mathrm{hPa}$. Figure 14(a) also shows contours of stream function anomaly, $\psi$, at $1000 \mathrm{hPa}$. Wind and pressure data are taken from the NCEP-DOE Reanalysis 2. For clarity, wind was regridded to $5^{\circ}$ resolution before plotting; horizontal divergence and $\psi$ were calculated directly from the wind field at the full $2.5^{\circ}$ resolution.

The Matsuno-Gill model (Matsuno, 1966; Gill, 1980) of the dynamical atmospheric response to diabatic heating in the Tropics has a solution in the form of equatorial Kelvin and Rossby waves, propagating eastwards and westwards respectively. These waves are bound by the equatorial waveguide - that is, their amplitude decays with meridional distance from the Equator. For example, for an equatorial Kelvin wave, the equatorial waveguide has an e-folding width of approximately $17^{\circ}$ latitude either side of the Equator; the islands of the Maritime Continent are within this waveguide.

In phase 2 the active MJO envelope is over the Indian Ocean; its eastern edge is just reaching the Maritime Continent (Figure 4). Figure 14(a) shows a tongue of low 

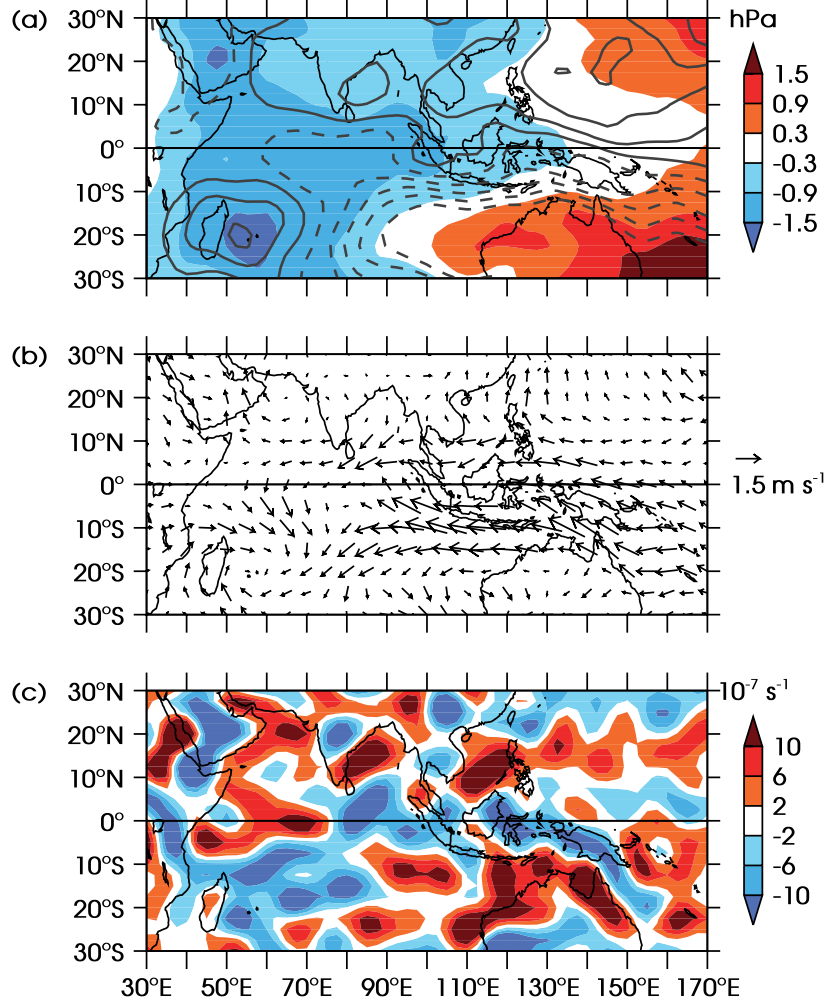

Figure 14. MJO phase 2 anomalies of (a) mean sea level pressure (hPa, shading) and stream function contours at $1000 \mathrm{hPa}$, starting a $\pm 2 \times 10^{5} \mathrm{~m}^{2} \mathrm{~s}^{-1}$ and drawn at $4 \times 10^{5} \mathrm{~m}^{2} \mathrm{~s}^{-1}$ intervals with positive (negative) contours solid (dashed); (b) wind arrows at $1000 \mathrm{hPa}$ (regridded to $5^{\circ}$ resolution for clarity); and (c) divergence $\left(10^{-7} \mathrm{~s}^{-1}\right.$, shading) at $1000 \mathrm{hPa}$ This figure is available in colour online at wileyonlinelibrary.com/journal/qj

pressure extending eastwards along the Equator from the region of anomalous heating, weakening to the east. This is consistent with an eastward-propagating equatorial Kelvin wave. There are also regions of low pressure extending northwestwards and southwestwards from the Equator, consistent with a westward-propagating equatorial Rossby wave. This matches the predicted pressure perturbation field in Figure 1(b) of Gill (1980). The off-equatorial pressure troughs associated with the Rossby wave response to the active convection have a corresponding pair of ridges in pressure to the east, arising from the Rossby wave response to the previous suppressed MJO envelope, which in phase 2 is over the west Pacific Ocean (Matthews, 2000). The anticyclonic flow associated with these regions of high pressure is seen around $120-140^{\circ} \mathrm{E}$ in the Northern Hemisphere and $80-100^{\circ} \mathrm{E}$ in the Southern Hemisphere (Figures 14(a) and (b)).

A reduction in the Coriolis force due to surface friction results in an ageostrophic component of the wind field into the equatorial pressure trough associated with the Kelvin wave. This results in a negative contribution to divergence from the meridional wind. Since the air is guaranteed to be moist over the warm oceans, this is an example of frictional moisture convergence (Hendon and Salby, 1994; Maloney and Hartmann, 1998). This occurs throughout the propagation of the MJO envelope. Furthermore there is an easterly wind anomaly on and around the Equator, due in part to the wind flowing down the pressure gradient associated with the Kelvin wave and in part to the anticyclonic vorticity associated with the Rossby wave extending from the west Pacific. Over the
Maritime Continent, this leads to horizontal convergence of air on the eastern flanks of mountains, for example in east Borneo and northeast New Guinea, as the flow is blocked by topography. Thus, the effect of topography enhances the effect of frictional moisture convergence to give particularly strong convergence over the islands, as seen in Figure 14(c).

We saw in Figure 4 that over the Maritime Continent itself the OLR anomaly in phase 2 is positive, indicating relatively clear skies. Therefore, the amount of short-wave radiation reaching the ground is enhanced, destabilizing the atmosphere; the low thermal inertia of the land allows the usual diurnal cycle to occur. The result of the strong convergence of moist air due to the wave dynamics described in the previous paragraph is a tendency to sustain this diurnal cycle convection, so that on average over the land this phase of the MJO is more convectively active than climatology. It may be speculated that the Kelvin wave response to the oncoming active convection is more dominant in this effect than the Rossby wave from the departing suppressed convection, since the peak in the diurnal cycle is just one WH04 phase ahead of the active envelope but three phases behind the suppressed envelope.

This mechanism also explains why there is no double peak in the amplitude of the diurnal cycle, as was suggested in section 5.1. Once the active envelope of the MJO is clear of the Maritime Continent, there are clear skies over the islands, causing the atmosphere to destabilize, but there is no longer frictional moisture convergence to sustain any convection, because the wave dynamics argument presented above applies but with a sign change (not shown). A peak of high pressure extends eastwards along the Equator, associated with a Kelvin wave forced by the negative heating anomaly over the Indian Ocean, and there are regions of offequatorial low pressure associated with the active envelope which is now over the west Pacific Ocean. These result in anomalous westerly flow near the Equator, and frictional moisture divergence as a reduction in Coriolis force causes air to flow out of the equatorial pressure peak, giving rise to a positive contribution to divergence from the meridional winds. Hence, the wave dynamics act to suppress the diurnal cycle when the active convection has passed through.

\section{Conclusions}

No strong consensus exists on the effect of the Madden-Julian Oscillation on the diurnal cycle of precipitation over the Maritime Continent. Here we have used 14 boreal winters of high-resolution brightness temperature and precipitation data along with an MJO index and used harmonic analysis to investigate the state of the diurnal cycle during each phase of the MJO. It was found that the amplitude $r_{\mathrm{d}}$ of the diurnal cycle changes by as much as $10 \mathrm{~mm} \mathrm{day}^{-1}$ over the land in opposite phases of the MJO cycle. It was found also that $r_{\mathrm{d}}$ is greatest shortly before the large-scale active MJO envelope arrives, with a lead time of a single WH04 phase or one-eighth of an MJO cycle, approximately six days (Figure 10). Furthermore, by computing MJO harmonics, it was shown that OLR does not act as a good proxy for the precipitation over the land; the brightness temperature does not peak until the large-scale MJO envelope arrives, even though the precipitation over the land is strongest one WH04 phase before that (Figure 13). This could be because the large-scale precipitation tends to be longer-lived than diurnal precipitation, so the convection is deeper, associated 
with a stronger OLR signal. It is possible that the effect is accentuated by the absence of extensive cirrus anvils from the diurnal cloud systems, which are present in the large-scale systems.

When the diurnal amplitude peaks, over land it is so strong that the diurnal cycle almost entirely accounts for the daily mean precipitation; in regions where there is a strong diurnal cycle about $80 \%$ of the MJO precipitation signal is accounted for by changes in the diurnal amplitude. Therefore, over the land to the east of the main MJO envelope the MJO precipitation signal is just the diurnal cycle precipitation. Hence there is a two-way scale interaction, in which the large-scale environment provided by the MJO modulates the diurnal cycle and the strength of the diurnal cycle modifies the structure of the MJO. A mechanism was proposed that is consistent with previous theories that describe the propagation of the MJO in terms of the equatorial wave response to diabatic convective heating. As the active MJO envelope just reaches the Maritime Continent, the eastwardpropagating equatorial Kelvin wave from the active region and the westward-propagating equatorial Rossby wave from the previous suppressed region combine to induce near-equatorial easterly anomalous flow. The influence of topography enhances the effect of frictional inflow to the pressure trough associated with the Kelvin wave. Together they provide frictional moisture convergence which is able to sustain a strong diurnal cycle over the land just to the east of the oncoming convection. When the MJO suppressed envelope is just reaching the Maritime Continent the reverse is true, and frictional moisture divergence acts to suppress the diurnal cycle. This is all in contrast to MJO propagation over open ocean, where the absence of land means there is no strong diurnal cycle to excite, and the MJO propagation is smoother.

The two-way scale interaction between the diurnal cycle and the MJO has consequences for forecasting precipitation in the region and for the simulation of the MJO in GCMs. In principle the organized structure and predictable propagation of the MJO gives us a rare opportunity in numerical weather prediction to forecast, for example, precipitation and the state of the large-scale wind field several weeks ahead. This compares with the theoretical limit for synoptic systems of one or two weeks, arising from the chaotic nature of the solutions to the governing equations. The MJO has also been observed to have an impact on other tropical weather features, such as tropical cyclones (e.g. Camargo et al., 2009), including hurricanes in the Gulf of Mexico (Maloney and Hartmann, 2000), and ENSO (e.g. Hendon et al., 2007); it also affects extratropical weather through teleconnections (e.g. Kim et al., 2006; Cassou, 2008). In the light of these impacts, the accurate modelling of the MJO takes on still further importance.

Current problems in the modelling of the MJO were described in section 1. It was stated that there is a 'systematic failure' in even the best-performing GCMs to simulate the eastward propagation over the region of the Maritime Continent. It is over the Maritime Continent that we have seen in this study the propagation mechanism of the MJO being changed in observations compared with propagation over the open Indian Ocean, where MJ events are initiated. Therefore, we propose an investigation into whether the land-based diurnal cycle of precipitation is excited at the correct stage of the MJO in GCMs, and whether introducing or improving the accuracy of such an excitation of the diurnal cycle acts to improve the simulation of the MJO. Model studies would also allow us to test the physical mechanism proposed here for the MJO phase lag between the diurnal cycle and the large-scale MJO envelope.

\section{Acknowledgements}

GLOBE topography data were downloaded from the web site of the NOAA-NGDC (http://www.ngdc.noaa.gov/mgg/ topo); TRMM $3 \mathrm{~B} 42$ precipitation and 3G01 brightness temperature data from NASA-Goddard (http://mirador. gsfc.nasa.gov and ftp://trmmopen.gsfc.nasa.gov respectively); and WH04 MJO index data from the Centre for Australian Weather and Climate Research (http://www. cawcr.gov.au/staff/mwheeler/maproom). NCEP-DOE Reanalysis 2 data were provided by the NOAA/OAR/ESRL PSD, Boulder, Colorado, USA, from their web site at http://www.esrl.noaa.gov/psd.

SCP was supported by a NERC PhD studentship. The research presented in this article was carried out on the High Performance Computing Cluster supported by the Research Computing Service at the University of East Anglia.

We thank two anonymous reviewers for comments which helped us to improve the manuscript significantly.

\section{References}

Batstone CP, Matthews AJ, Stevens DP. 2005. Coupled oceanatmosphere interactions between the Madden-Julian Oscillation and synoptic-scale variability over the warm pool. J. Climate 18: 2004-2020.

Camargo SJ, Wheeler MC, Sobel AH. 2009. Diagnosis of the MJO modulation of tropical cyclogenesis using an empirical index. J. Atmos. Sci. 66: 3061-3074.

Cassou C. 2008. Intraseasonal interaction between the Madden-Julian oscillation and the North Atlantic Oscillation. Nature 455: 523-527. DOI: $10.1038 /$ nature 07286

Chen SS, Houze RA. 1997. Diurnal variation and life-cycle of deep convective systems over the tropical Pacific warm pool. Q. J. R. Meteorol. Soc. 123: 357-388.

Gill AE. 1980. Some simple solutions for heat-induced tropical circulation. Q. J. R. Meteorol. Soc. 106: 447-462.

GLOBE Task Team. 'The Global Land One-kilometer Base Elevation (GLOBE) Digital Elevation Model, version 1.0'. 1999.

Hastings DA, Dunbar PK, Elphingstone GM, Bootz M, Murakami H, Maruyama H, Masaharu H, Holland P, Payne J, Bryant NA, Logan TL, Muller J-P, Schreier G, MacDonald JS. (eds) National Oceanic and Atmospheric Administration, National Geophysical Data Center: Boulder, CO, USA. Digital database at http://www.ngdc.noaa.gov/mgg/topo/globe.html and on CD-ROMs.

Gray WM, Jacobson RW. 1977. Diurnal variation of deep cumulus convection. Mon. Weather Rev. 105: 1171-1188.

Hendon HH, Salby ML. 1994. The life cycle of the Madden-Julian Oscillation. J. Atmos. Sci. 51: 2225-2237.

Hendon HH, Wheeler MC, Zhang C. 2007. Seasonal dependence of the MJO-ENSO relationship. J. Climate 20: 531-543.

Huffman GJ, Bolvin DT, Nelkin EJ, Wolff DB, Adler RF, Gu G, Hong Y, Bowman KP, Stocker EF. 2007. The TRMM Multisatellite Precipitation Analysis (TMPA): Quasi-global, multiyear, combinedsensor precipitation estimates at fine scales. J. Hydrometeorol. 8: 38-55.

Ichikawa H, Yasunari T. 2008. Intraseasonal variability in diurnal rainfall over New Guinea and the surrounding oceans during austral summer. J. Climate. 21: 2852-2868.

Kanamitsu M, Ebisuzaki W, Woollen J, Yang S-K, Hnilo JJ, Fiorino M, Potter GL. 2002. NCEP-DOE AMIP-II Reanalysis (R-2). Bull. Amer. Meteorol. Soc. 83: 1631-1643.

Kim B-M, Lim G-H, Kim K-Y. 2006. A new look at the midlatitude-MJO teleconnection in the Northern Hemisphere winter. Q. J. R. Meteorol. Soc. 132: 485-503.

Kummerow C, Barnes W, Kozu T, Shiue J, Simpson J. 1998. The Tropical Rainfall Measuring Mission (TRMM) sensor package. J. Atmos. Oceanic Technol. 15: 809-817. 
Lin J-L, Kiladis GN, Mapes BE, Weickmann KM, Sperber KR, Lin W, Wheeler MC, Schubert SD, Del Genio A, Donner LJ, Emori S, Gueremy J-F, Hourdin F, Rasch PJ, Roeckner E, Scinocca JF. 2006. Tropical intraseasonal variability in 14 IPCC AR4 climate models. Part I: convective signals. J. Climate 19: 2665-2690.

Love BS, Matthews AJ, Lister GMS. 2011. The diurnal cycle of precipitation over the Maritime Continent in a high-resolution atmospheric model. Q. J. R. Meteorol. Soc. 137: 934-947.

Madden RA, Julian PR. 1971. Detection of a 40-50 day oscillation in the zonal wind in the tropical Pacific. J. Atmos. Sci. 28: 702-708.

Madden RA, Julian PR. 1972. Description of global-scale circulation cells in the tropics with a 40-50 day period. J. Atmos. Sci. 29: 1109-1123.

Madden RA, Julian PR. 1994. Observations of the 40-50 day tropical oscillation - a review. Mon. Weather Rev. 122: 814-837.

Maloney ED, Hartmann DL. 1998. Frictional moisture convergence in a composite life cycle of the Madden-Julian Oscillation. J. Climate 11: 2387-2403.

Maloney ED, Hartmann DL. 2000. Modulation of hurricane activity in the Gulf of Mexico by the Madden-Julian Oscillation. Science 287: 2002-2004.

Matsuno T. 1966. Quasi-geostrophic motions in the equatorial area. J. Meteorol. Soc. Japan 44: 25-43.

Matthews AJ. 2000. Propagation mechanisms for the Madden-Julian Oscillation. Q. J. R. Meteorol. Soc. 126: 2637-2651.

Mori S, Jun-Ichi H, Iman Tauhid Y, Yamanaka MD, Okamoto N, Murata F, Sakurai N, Hashiguchi H, Sribimawati T. 2004. Diurnal land-sea rainfall peak migration over Sumatera island, Indonesian Maritime Continent, observed by TRMM satellite and intensive rawinsonde soundings. Mon. Weather Rev. 132: 2021-2039.

Neale R, Slingo JM. 2003. The Maritime Continent and its role in the global climate: A GCM study. J. Climate 16: 834-848.

Nesbitt SW, Zipser EJ. 2003. The diurnal cycle of rainfall and convective intensity according to three years of TRMM measurements. J. Climate 16: $1456-1475$.

Oh J-H, Kim K-Y, Lim G-H. 2012. Impact of MJO on the diurnal cycle of rainfall over the western Maritime Continent in the austral summer. Clim. Dyn. 38: 1167-1180.
Qian J-H. 2008. Why precipitation is mostly concentrated over islands in the Maritime Continent. J. Atmos. Sci. 65: 1428-1441.

Ramage CS. 1968. Role of a tropical 'Maritime Continent' in the atmospheric circulation. Mon. Weather Rev. 96: 365-370.

Rauniyar SP, Walsh KJE. 2011. Scale interaction of the diurnal cycle of rainfall over the Maritime Continent and Australia: Influence of the MJO. J. Climate 24: 325-348.

Simpson J, Keenan TD, Ferrier B, Simpson RH, Holland GJ. 1993. Cumulus mergers in the Maritime Continent region. Meteorol. Atmos. Phys. 51: 73-99. DOI: 10.1007/BF01080881

Simpson J, Kummerow C, Tao W-K, Adler RF. 1996. On the Tropical Rainfall Measuring Mission (TRMM). Meteorol. Atmos. Phys. 60: 19-36. DOI: 10.1007/BF01029783.

Sperber KR, Slingo JM, Inness PM, Lau WK-M. 1997. On the maintenance and initiation of the intraseasonal oscillation in the NCEP/NCAR reanalysis and the GLA and UKMO AMIP simulations. Clim. Dyn. 13: 769-795.

Sui C-H, Lau K-M. 1992. Multiscale phenomena in the tropical atmosphere over the western Pacific. Mon. Weather Rev. 120: 407-430.

Sui C-H, Li X, Lau K-M, Adamec D. 1997. Multiscale air-sea interactions during TOGA COARE. Mon. Weather Rev. 125: 448-462.

Suzuki T. 2009. Diurnal cycle of deep convection in super clusters embedded in the Madden-Julian Oscillation. J. Geophys. Res. 114: D22102. DOI: 10.1029/2008JD011303

Tian B, Waliser DE, Fetzer EJ. 2006. Modulation of the diurnal cycle of tropical deep convective clouds by the MJO. Geophys. Res. Lett. 33: L20704. DOI: 10.1029/2006GL027752

Wheeler MC, Hendon HH. 2004. An all-season real-time multivariate MJO index: Development of an index for monitoring and prediction. Mon. Weather Rev. 132: 1917-1932.

Wilks DS. 2011. Statistical methods in the atmospheric sciences. Academic Press.

Yang G-Y, Slingo J. 2001. The diurnal cycle in the tropics. Mon. Weather Rev. 129: 784-801.

Zhang C. 2005. Madden-Julian oscillation. Rev. Geophys. 43: RG2003. DOI: $10.1029 / 2004 R G 000158$ 